\title{
The tensile properties of poly(ethylene oxide)-based segmented block copolymers in the dry and wet state
}

\author{
D. Husken · R. J. Gaymans
}

Received: 8 September 2008/Accepted: 17 February 2009/Published online: 13 March 2009

(C) The Author(s) 2009. This article is published with open access at Springerlink.com

\begin{abstract}
The tensile properties of poly(ethylene oxide)based segmented block copolymers were studied in the dry and wet state. The hard segments were made up of monodisperse crystallisable tetra-amide segments (T6T6T) comprising terephthalate (T) and hexamethylenediamine (6) groups. The length of the segments making up the soft phase was varied from 600 to $10,000 \mathrm{~g} / \mathrm{mol}$. The water absorption of the PEO-based copolymers was found to increase exponentially with the PEO concentration. The modulus and yield strength decreased with water absorption and this effect seemed to be mainly the result of a lowering hard segment content caused by their swelling with water. Upon wetting, the copolymers demonstrated an increased yield strain. Furthermore, the ultimate properties were sensitive to the hard segment content, the molecular weight of the copolymer and whether or not strain-hardening could take place. Upon wetting, the fracture stresses decreased whereas the fracture strains increased. The true fracture stresses of the wet samples were as high as those of the dry samples for reasonable amounts of absorbed water.
\end{abstract}

\section{Introduction}

Poly(ethylene oxide)-containing copolymers are hydrophilic materials that are of interest for numerous application areas, including the fields of textiles, packaging, construction, gas

D. Husken · R. J. Gaymans ( $\square)$

Department of Science and Technology, University of Twente, P.O. Box 217, 7500 AE Enschede, The Netherlands

e-mail: r.j.gaymans@utwente.nl

D. Husken

Dutch Polymer Institute, P.O. Box 902, 5600 AX Eindhoven,

The Netherlands separation and biomedical. There exist several reports on PEO-based segmented block copolymers with hard segment types such as esters [1-4], amides [5-7] or urethanes (urea) [7-14]. Pure poly(ethylene oxide) (PEO) at room temperature is completely soluble in water, in contrast to other closely related polyethers, e.g., poly(tetramethylene oxide) or poly(propylene oxide), and this solubility can be explained by the strong interaction between water and PEO [15]. The PEO copolymers absorb a considerable amount of water, which affects the material properties. Regardless of the intended use, the knowledge of the mechanical properties of segmented block copolymers in both the dry and the wet state is very important.

Dry PEO copolymers have been found to display a yield stress at low strains and a strain-hardening at higher strains. In certain cases, an extra hardening can be observed if the PEO segments strain-crystallise at strains above $200 \%$. Upon wetting, the modulus, yield stress, fracture stress and fracture strain become lower as a result of the absorbed water acting as a plasticiser and decreasing the glass transition temperature of the polymer [11, 16-20].

The properties of the segmented block copolymers depend on the morphology. Polyurethane-based segmented block copolymers phase separate through liquid-liquid demixing, and this is often followed by a partial crystallisation of the hard segments. Hard segments that crystallise rapidly, such as polyesters and polyamides, usually phase separate by crystallisation. However, the crystallinity of these hard segments in the segmented block copolymers is generally low and a large amount of non-crystallised hard segments is present in the polyether matrix. The crystallisation and the stability of the hard segments are improved when the segments are monodisperse in length [21-33]. Short monodisperse amide segments crystallise fast and almost completely. With such short monodisperse amide 
Fig. 1 The chemical structures of $\mathrm{PEO}_{x},\left(\mathrm{PEO}_{600} / \mathrm{T}\right)_{y}$ and T6T6T

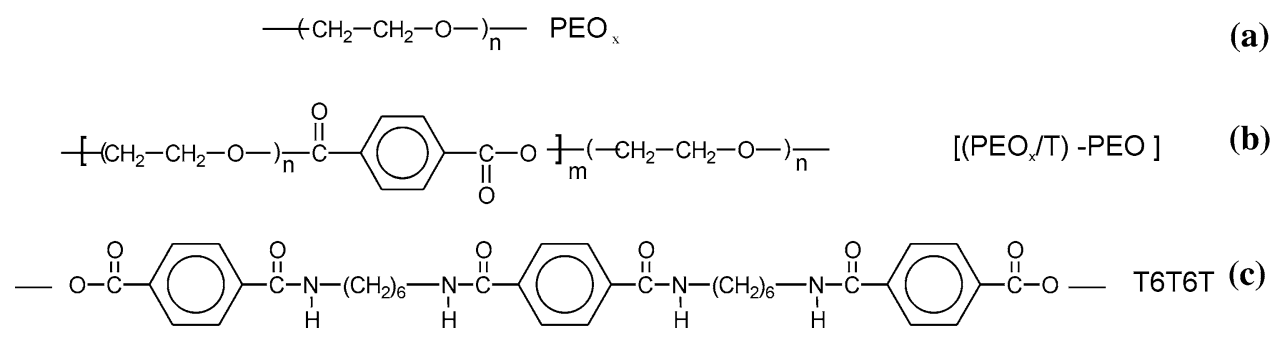

(a) segments, the modulus in the dry state of these copolymers has been found to be relatively elevated and the polyether concentration in the copolymer can be high, up to $88 \mathrm{wt} \%$ [34, 35].

The water absorption of PEO copolymers increases asymptotically with the PEO content, thus naturally leading to a larger number of water molecules per ethylene oxide unit $\left(\mathrm{H}_{2} \mathrm{O} / \mathrm{EO}\right)$ [36]. With such water absorption, the $T_{\mathrm{g}}$ and $T_{\mathrm{m}}$ of the PEO phase are reduced.

The present article reports on the investigation of segmented block copolymers based on hydrophilic PEO segments and short monodisperse crystallisable tetra-amide (T6T6T) segments comprising terephthalic acid (T) and hexamethylenediamine (6) (Fig. 1).

The T6T6T segments in segmented block copolymers crystallised near fully $(\sim 85 \%)$ and had a nano-ribbon morphology with a high aspect ratio [27, 28, 33]. The reinforcing effects of these nano-ribbon crystallites have followed the composite models [28, 33]. Two copolymer series were evaluated, one with $\mathrm{PEO}_{x}$ segments (Fig. 1a), denoted $\mathrm{PEO}_{x}-\mathrm{T} 6 \mathrm{~T} 6 \mathrm{~T}$ [34], and another series containing $\mathrm{PEO}_{600}$ segments that were extended with terephthalic units $(\mathrm{T})\left(-\left(\mathrm{PEO}_{600} / \mathrm{T}\right)_{y}-\right)$, whereby the $x$ and $y$ values are the segmental molecular weights (Fig. 1b) [35]. The terephthalate units were miscible with the PEO phase and thus increased the soft segment length. The long $-\left(\mathrm{PEO}_{600} / \mathrm{T}\right)_{y}-$ segments and T6T6T were found not to phase separate by liquid-liquid demixing upon synthesis, and the crystallinity of the $-\left(\mathrm{PEO}_{600} / \mathrm{T}\right)_{y}$ - segments was considered low with respect to the segment length. The physical properties, i.e., the glass transition temperature of the soft phase, the PEO melting temperature and the crystallinity, were determined by differential scanning calorimetry (DSC), and the tensile properties of these hydrophilic copolymers were studied in the dry and the wet state.

\section{Experimental}

\section{Materials}

The synthesis, analysis and characterisation of various properties of the $\mathrm{PEO}_{2000}-\mathrm{T} 6 \mathrm{~T} 6 \mathrm{~T}$ and $\left(\mathrm{PEO}_{600} / \mathrm{T}\right)_{y}-\mathrm{T} 6 \mathrm{~T} 6 \mathrm{~T}$ copolymers have been studied previously and are reported elsewhere [34, 35].
Water absorption

The equilibrium water absorption (WA) was measured on pieces of injection-moulded polymer bars $\left(70 \times 9 \times 2 \mathrm{~mm}^{3}\right)$. The samples were placed in a desiccator filled with demineralised water during a time period of 4 weeks at room temperature. The water absorption was defined as the weight gain of the polymer according to:

Water absorption $=\frac{m-m_{0}}{m_{0}} \times 100 \%(\mathrm{wt} \%)$

where $m_{0}$ is the weight of the dry sample and $m$ the weight of the sample after conditioning to equilibrium. The measurements were performed in duplicates. After 4 weeks, the samples were dried and $m_{0}$ was remeasured so as to exclude weight loss during the experiment. From these data, the number of water molecules per ethylene oxide unit $\left(\mathrm{H}_{2} \mathrm{O} / \mathrm{EO}\right)$ was also calculated.

\section{Differential scanning calorimetry (DSC)}

The thermal transitions of the dry and hydrated copolymers were determined by DSC using a Pyris 1 (Perkin Elmer, USA). The analyses were run on small pieces of the injection-moulded polymer bars $(5-10 \mathrm{mg})$. The samples were kept for $1 \mathrm{~min}$ at $-100{ }^{\circ} \mathrm{C}$ and subsequently heated from -100 to $80{ }^{\circ} \mathrm{C}$ at a heating rate of $10{ }^{\circ} \mathrm{C} / \mathrm{min}$. This first heating scan was followed by a cooling scan from 80 to $-100{ }^{\circ} \mathrm{C}$ at a rate of $10{ }^{\circ} \mathrm{C} / \mathrm{min}$ and a subsequent second heating scan under the same conditions as the first. The glass transition temperature was taken as the midpoint of the heat capacity change of the first heating scan. In the case of completely hydrated polymers, the samples were placed in demineralised water for 1 day in order to reach an equilibrium water absorption state. The excess water was gently removed using an absorbing tissue paper.

\section{Tensile testing}

Samples for tensile testing were prepared by melt-spinning of the dried polymer into threads on a 4 cc DSM res RD11H-1009025-4) co-rotating twin screw mini-extruder. The extrusion temperature was set approximately $40{ }^{\circ} \mathrm{C}$ above the flow temperature of the copolymer and the screw 
speed to $30 \mathrm{rpm}$. The titre of the threads (expressed in tex $=10^{-6} \mathrm{~kg} / \mathrm{m}$ ) was calculated assuming a polymer density of $1.0 \mathrm{~g} / \mathrm{cm}^{3}$. Tensile tests were carried out on the threads with a Zwick Z020 universal tensile machine equipped with a $10 \mathrm{~N}$ load cell. The strain was measured by clamp displacement, and standard stress-strain curves were obtained at a strain rate of $250 \mathrm{~mm} / \mathrm{min}$ with a starting clamp distance of $25 \mathrm{~mm}$. The tests were performed in 5-fold, and values of initial modulus, yield stress and yield strain, fracture stress and fracture strain, as well as true fracture stress were determined. The true fracture stress was defined as the fracture stress $\times$ (the fracture strain +1 ) assuming that the volume of the sample did not change on straining. The dry polymers had an $E / G$ ratio of three and thus behaved like ideal rubbers. Tensile tests were also performed on hydrated polymer threads that had been placed in demineralised water for 1 day to reach an equilibrium state of water absorption. The observed standard deviation in the data was approximately $10 \%$. For the wet samples the true fracture stresses were also determined assuming that they also behaved like ideal rubbers.

\section{Results and discussion}

PEO-T6T6T segmented block copolymers were prepared in a solution-melt process and were found to have high inherent viscosities. The amide copolymers were poorly soluble in most solvents, but could however be dissolved in trifluoroacetic acid and a mixture of tetra-chloro-ethane/ phenol. The determination of the $M_{n}$ values for the amidecontaining copolymers was very difficult. GPC was a possible technique, but the values for amide copolymers are often overestimated. Maldi-TOF could not be used as the copolymers did not fly due to the amide segments. NMR can sometimes be used to determine the end-group content, but for higher molecular weights, this method is inaccurate.

Eventually, solution viscosities could be determined in tetra-chloro-ethane/phenol mixtures and these measurements proved to be very reproducible. The inherent viscosities were determined at low polymer concentrations, and the inherent viscosity values at low concentrations were virtually the same as those of the intrinsic viscosity. For amide polymers and copolymers, the inherent viscosities usually increase linearly with the molecular weight [15]. For polyethers, the relationship of $M_{n}$ (as determined by NMR) and the inherent viscosity, according to [37, 38]:

$M_{n}=10.700 \eta_{\text {inh }}$

can be applied to polymers for which the molecular weights are not too high. This relationship corresponded well with that for polyamides. Under the assumption that this relationship was permitted, the molecular weights of the copolymers could be approximated. Moreover, the number of hard segments (HS) in the chain for these multiblock copolymers could be estimated. Table 1 presents these and various other properties of the $\mathrm{PEO}_{x}$-T6T6T and $\left(\mathrm{PEO}_{600} / \mathrm{T}\right)_{y}-\mathrm{T} 6 \mathrm{~T} 6 \mathrm{~T}$ copolymers.

PEO-based segmented block copolymers

The water absorption (WA) of two series of PEO-based copolymers, i.e., the $\mathrm{PEO}_{x}-\mathrm{T} 6 \mathrm{~T} 6 \mathrm{~T}$ and $\left(\mathrm{PEO}_{600} / \mathrm{T}\right)_{y}-$ T6T6T series, was investigated (Table 1).

Because of the high T6T6T crystallinity in the copolymers $(\sim 85 \%)$ and the fact that crystalline nylon does not absorb water [39], it was assumed that water was only absorbed in the PEO phase of the copolymers (Fig. 2).

As can be seen in Fig. 2, the water absorption at $100 \%$ relative humidity $(\mathrm{RH})$ increased exponentially as a function of the PEO content. This strong increase in water

Table 1 Various properties of $\mathrm{PEO}_{x}$-T6T6T and $\left(\mathrm{PEO}_{600} / \mathrm{T}\right)_{y}$-T6T6T copolymers

\begin{tabular}{|c|c|c|c|c|c|c|c|c|c|c|c|c|}
\hline $\begin{array}{l}x \text { or } y \\
(\mathrm{~g} / \mathrm{mol})\end{array}$ & $\begin{array}{l}\text { Conc. } \\
\text { T6T6T } \\
\text { (wt\%) }\end{array}$ & $\begin{array}{l}\text { Conc. } \\
\text { PEO } \\
\text { (wt\%) }\end{array}$ & $\begin{array}{l}\text { Conc. T } \\
(\mathrm{wt} \%)\end{array}$ & $\begin{array}{l}\eta_{\text {inh }} \\
(\mathrm{dL} / \mathrm{g})\end{array}$ & $\begin{array}{l}\text { HS } \\
\text { per } \\
\text { chain }\end{array}$ & $\begin{array}{l}\text { WA } \\
\text { (wt } \%)\end{array}$ & $\mathrm{H}_{2} \mathrm{O} / \mathrm{EO}$ & $\begin{array}{l}T_{\mathrm{g}} \text { PEO } \\
\text { dry } \\
\left({ }^{\circ} \mathrm{C}\right)\end{array}$ & $\begin{array}{l}T_{\mathrm{g}} \text { PEO } \\
\text { wet } \\
\left({ }^{\circ} \mathrm{C}\right)\end{array}$ & $\begin{array}{l}T_{\mathrm{m}} \text { PEO } \\
\text { dry } \\
\left({ }^{\circ} \mathrm{C}\right)\end{array}$ & $\begin{array}{l}T_{\mathrm{m}} \text { PEO } \\
\text { wet } \\
\left({ }^{\circ} \mathrm{C}\right)\end{array}$ & $\begin{array}{l}T_{\mathrm{m}} \\
\text { T6T6T } \\
\left({ }^{\circ} \mathrm{C}\right)\end{array}$ \\
\hline \multicolumn{13}{|c|}{$P E O_{x}-T 6 T 6 T$} \\
\hline 600 & 51.0 & 49.0 & 0 & 1.4 & 12 & 18 & 0.9 & -42 & -58 & $\mathrm{np}$ & np & 219 \\
\hline 2000 & 23.8 & 76.2 & 0 & 1.9 & 7.7 & 91 & 2.9 & -53 & -70 & 14 & -39 & 167 \\
\hline \multicolumn{13}{|c|}{$\left(P E O_{600} / T\right)_{y}-T 6 T 6 T$} \\
\hline 600 & 51.0 & 49.0 & 0 & 1.4 & 12 & 18 & 0.9 & -42 & -58 & $\mathrm{np}$ & np & 219 \\
\hline 1250 & 33.3 & 60.4 & 6.3 & 1.6 & 9.0 & 30 & 1.2 & -40 & -60 & $\mathrm{np}$ & $\mathrm{np}$ & 208 \\
\hline 2500 & 20.0 & 69.0 & 11.0 & 1.7 & 5.8 & 49 & 1.7 & -44 & -55 & -6 & -26 & 187 \\
\hline 5000 & 11.1 & 74.8 & 14.1 & 1.5 & 2.8 & 69 & 2.2 & -43 & -63 & -3 & np & 171 \\
\hline 10000 & 5.9 & 78.1 & 16.0 & 1.5 & 1.5 & 75 & 2.3 & -44 & - & -2 & - & 158 \\
\hline
\end{tabular}

$n p$ not present 


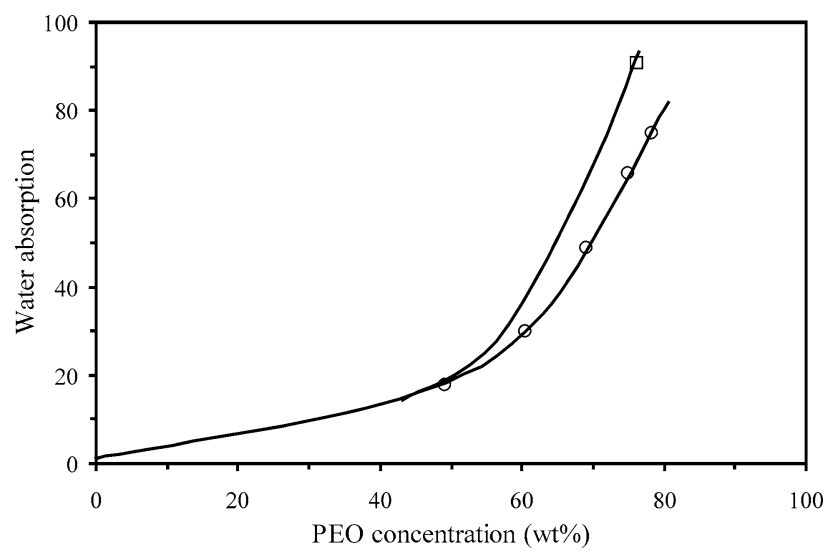

Fig. 2 The equilibrium water absorption (WA) as a function of the PEO concentration for: $\square \mathrm{PEO}_{2000}-\mathrm{T} 6 \mathrm{~T} 6 \mathrm{~T}, \bigcirc\left(\mathrm{PEO}_{600} / \mathrm{T}\right)_{y}-\mathrm{T} 6 \mathrm{~T} 6 \mathrm{~T}$

absorption can be explained as being due to both the PEO content and the decreasing density of physical crosslinks, i.e., the length of polyether between T6T6T segments [36]. The water absorption for the $\left(\mathrm{PEO}_{600} / \mathrm{T}\right)_{y}-\mathrm{T} 6 \mathrm{~T} 6 \mathrm{~T}$ copolymers was lower than for $\mathrm{PEO}_{x}-\mathrm{T} 6 \mathrm{~T} 6 \mathrm{~T}$, indicating that the presence of terephthalic units in the amorphous phase reduced the water absorption. Moreover, the number of water molecules per ethylene oxide unit $\left(\mathrm{H}_{2} \mathrm{O} / \mathrm{EO}\right)$ was calculated and this value was found to vary from 0.9 to 2.9 between the various copolymers.

\section{Effect of water on the PEO phase transitions}

Water is known to act as a plasticiser in PEO copolymers and depress the glass transition temperature of the PEO phase [40-42]. The glass transition temperatures of dry and completely hydrated PEO copolymers were measured by DSC $\left(10{ }^{\circ} \mathrm{C} / \mathrm{min}\right)$ and the results are summarised in Table 1 . The $\mathrm{PEO}_{600}$ displayed a relatively elevated $T_{\mathrm{g}}$ and this can be explained by the high density of physical crosslinks. The $T_{\mathrm{g}}$ values of the copolymers with a $\left(\mathrm{PEO}_{600} / \mathrm{T}\right)_{y}$ increased a bit with the soft segment (SS) length. The $T_{\mathrm{g}}$ for $\left(\mathrm{PEO}_{600} / \mathrm{T}\right)_{y}$ with a $y$-value corresponding to about $2000 \mathrm{~g} / \mathrm{mol}$ was, in the dry state, approx. $9^{\circ}$ higher than the value for $\mathrm{PEO}_{2000}$. This $9{ }^{\circ} \mathrm{C}$ shift in $T_{\mathrm{g}}$ caused by the presence of the terephthalate groups corresponded to previous observations [27, 43]. Upon wetting, the $T_{\mathrm{g}}$ values shifted to lower temperatures, and this phenomenon was due to the plasticising effect of water on the PEO segments. The difference in $T_{\mathrm{g}}$ between dry and wet copolymers for $\mathrm{PEO}_{2000}$ and $\mathrm{PEO}_{600}$ was $22-25{ }^{\circ} \mathrm{C}$ for both copolymers and thus almost independent of the amount of absorbed water as well as of the $\mathrm{H}_{2} \mathrm{O} / \mathrm{EO}$ ratio.

The PEO melting temperature increased with increasing PEO segment length, but was lowered in the presence of terephthalate groups [35]. In the dry state, $\mathrm{PEO}_{2000}$ demonstrated a melting temperature of $14{ }^{\circ} \mathrm{C}$ whereas that of $\left(\mathrm{PEO}_{600} / \mathrm{T}\right)_{y}$ ranged from -2 to $-6{ }^{\circ} \mathrm{C}$. Upon wetting, the $\mathrm{PEO}_{2000}$ copolymer displayed a decrease in $T_{\mathrm{m}}$ to $-39{ }^{\circ} \mathrm{C}$, and the $T_{\mathrm{m}}$ of the $\left(\mathrm{PEO}_{600} / \mathrm{T}\right)_{2500}$ segment was $-26^{\circ} \mathrm{C}$. On the contrary, for the other $\left(\mathrm{PEO}_{600} / \mathrm{T}\right)_{y}$ samples in the wet state, no $T_{\mathrm{m}}$ could be detected, possibly due to an overlap between peaks. The lowering of the $T_{\mathrm{m}}$ of PEO in the presence of water was due to the solvent effect of water on the PEO crystallites.

With increasing water content, the reduction in the PEO melting temperature was stronger than that of the glass transition temperature. Thus, upon wetting, the $T_{\mathrm{g}} / T_{\mathrm{m}}$ ratio increased from 0.77 to 0.81 for the $\mathrm{PEO}_{2000}-\mathrm{T} 6 \mathrm{~T} 6 \mathrm{~T}$ copolymer. Generally, a higher $T_{\mathrm{g}} / T_{\mathrm{m}}$ ratio results in a reduced crystallisation rate and crystallinity [44].

\section{Tensile properties}

The choice was made to analyse the tensile properties of the copolymers on threads instead of dumbbell-shaped bars for two reasons. The first was that the amount of available material was limited, and the second was that threads have very smooth surfaces, thus resulting in the data being less influenced by surface inhomogeneities.

The tensile properties of the PEO-T6T6T segmented copolymers were studied on dry and wet samples and typical stress-strain curves can be seen in Fig. 3. At small deformations, the stress displayed a linear increase with the strain. No necking was observed at the yield point and the samples deformed homogenously. Above the yield point, the stress continued to gradually increase with the strain.

The increase in strain was due to a strain-hardening process. In certain cases, such as for the $\mathrm{PEO}_{600}-\mathrm{T} 6 \mathrm{~T} 6 \mathrm{~T}$, an extra increase in stress was observed at strains above 200\%. This extra strain-hardening was believed to have been due to a strain-induced crystallisation of the polyether segments. The strain-hardening stabilised the deformation and increased the fracture stress [18]. Both the basic strain hardening as well as the strain-induced PEO crystallisation process decreased with increasing segment length of $\left(\mathrm{PEO}_{600} / \mathrm{T}\right)_{y}$, thereby decreasing the T6T6T concentration. For stress-induced crystallisation, the melting temperature of the soft (oriented) phase should be above the test temperature. However, the isotropic melting temperature of the polyether phase did not have to be above room temperature since, upon orientation, the melting temperature could increase by several tens of degrees [43]. Since water reduced the melting temperature of PEO, the strain-induced crystallisation of the PEO segments should become more difficult. In order to study the influence of water on the tensile properties of the PEO-T6T6T copolymers, an investigation was carried out on copolymers with a PEO 

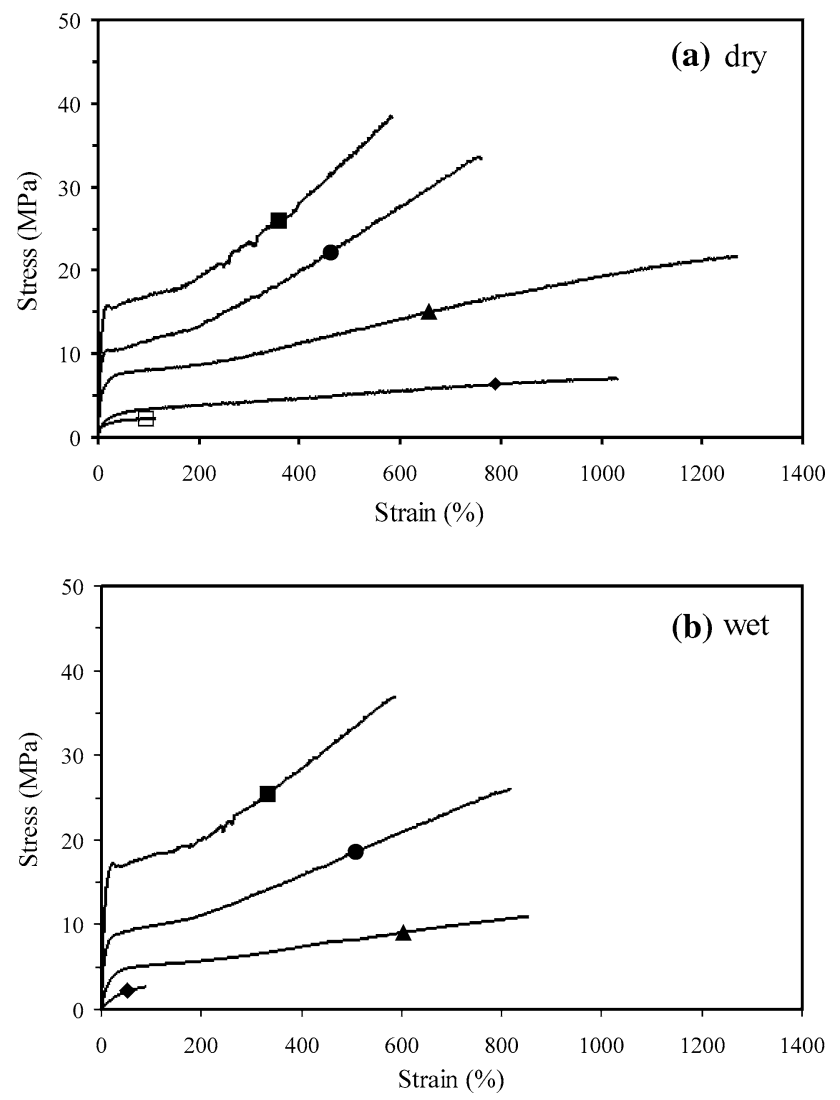

Fig. 3 Typical stress-strain diagrams of $\mathbf{a}$ dry and $\mathbf{b}$ wet samples of $\left(\mathrm{PEO}_{600} / \mathrm{T}\right)_{\underline{y}}-\mathrm{T} 6 \mathrm{~T} 6 \mathrm{~T}: \boldsymbol{\square} 600, \bullet 1250, \boldsymbol{\Delta} 2500, \diamond 5000, \square 10000$

melting temperature in the isotropic state below room temperature. The results of these tensile tests are summarised in Table 2.

\section{Modulus}

The modulus of segmented block copolymers depends on the modulus of the soft phase, the network density and the reinforcement of the matrix by the HS crystallites [45]. Figure 4 presents the $E$ - and $G^{\prime}$-moduli as functions of the T6T6T content in the $\left(\mathrm{PEO}_{600} / \mathrm{T}\right)_{y}-\mathrm{T} 6 \mathrm{~T} 6 \mathrm{~T}$ copolymers, and as can be seen from the figure, the $E$-modulus of the studied PEO copolymers in the dry state increased significantly with increasing T6T6T concentration, as did the $G^{\prime}$-modulus.

As previously observed, the type of soft segment, i.e., $\mathrm{PEO}_{2000}$ or $\left(\mathrm{PEO}_{600} / \mathrm{T}\right)_{y}$, had little effect on the modulus [35]. The increase in $E$-modulus with HS content was thus mainly caused by the reinforcing effect of the HS crystallites. The $E$-modulus is related to the storage modulus $\left(G^{\prime}\right)$ according to Eq. 3.

$G^{\prime}=\frac{E}{2}(1+v)$

where $v$ is the Poisson constant. In the case of an ideal elastomer, the Poisson constant equals 0.5 and thus $G^{\prime}=3 E$. According to the $E$ - and $G^{\prime}$-modulus values from Fig. $4, G^{\prime}$ could be approximated with $3 E$ for a majority of the copolymers and thus behaved like ideal rubbers. Upon wetting, the $E$-modulus was found to decrease with increasing water content (Table 2). As water was absorbed, the PEO phase was plasticised and the T6T6T concentration in the system reduced. The samples thus became swollen and the concentration of the HS was lowered (Table 2). In order to single out the T6T6T concentration effect obtained from the water absorption on the

Table 2 Tensile properties in the dry and wet state of the $\mathrm{PEO}_{2000}-\mathrm{T} 6 \mathrm{~T} 6 \mathrm{~T}$ and $\left(\mathrm{PEO}_{600} / \mathrm{T}\right)_{y}$-T6T6T copolymers

\begin{tabular}{|c|c|c|c|c|c|c|c|c|c|c|c|}
\hline $\begin{array}{l}\text { SS length } \\
(\mathrm{g} / \mathrm{mol})\end{array}$ & $\begin{array}{l}\eta_{\text {inh }} \\
(\mathrm{dL} / \mathrm{g})\end{array}$ & $\begin{array}{l}\text { WA } \\
\text { (wt } \%)\end{array}$ & $\begin{array}{l}\text { Conc. T6T6T } \\
\text { (wt } \%)\end{array}$ & $\mathrm{H}_{2} \mathrm{O} / \mathrm{EO}$ & $\begin{array}{l}\mathrm{G}^{\prime} \\
(\mathrm{Mpa})\end{array}$ & $\begin{array}{l}\mathrm{E} \\
(\mathrm{MPa})\end{array}$ & $\begin{array}{l}\sigma_{y}^{\mathrm{a}} \\
(\mathrm{MPa})\end{array}$ & $\begin{array}{l}\varepsilon_{y}^{\mathrm{a}} \\
(\%)\end{array}$ & $\begin{array}{l}\sigma_{f} \\
(\mathrm{MPa})\end{array}$ & $\begin{array}{l}\varepsilon_{f} \\
(\%)\end{array}$ & $\begin{array}{l}\sigma_{\text {true }}^{\mathrm{b}} \\
(\mathrm{MPa})\end{array}$ \\
\hline \multicolumn{12}{|c|}{$\mathrm{PEO}_{2000}-\mathrm{T6T6T}$} \\
\hline \multirow[t]{2}{*}{2000} & 1.9 & 0 & 23.8 & 0 & 38 & 117 & 6.3 & 27 & 27 & 920 & 275 \\
\hline & & 91 & 12.5 & 2.9 & - & 20 & 5.4 & 67 & 14 & 490 & 100 \\
\hline \multicolumn{12}{|c|}{$\left(P E O_{600} / T\right)_{y}-T 6 T 6 T$} \\
\hline \multirow[t]{2}{*}{600} & 1.4 & 0 & 51.0 & 0 & 160 & 263 & 15.5 & 17 & 32 & 490 & 189 \\
\hline & & 18 & 43.2 & 0.9 & - & 216 & 16.8 & 16 & 36 & 520 & 223 \\
\hline \multirow[t]{2}{*}{1250} & 1.6 & 0 & 33.3 & 0 & 68 & 233 & 10.8 & 13 & 27 & 710 & 219 \\
\hline & & 30 & 25.6 & 1.2 & - & 130 & 8.7 & 21 & 26 & 780 & 229 \\
\hline \multirow[t]{2}{*}{2500} & 1.7 & 0 & 20.0 & 0 & 32 & 81 & 5.9 & 24 & 19 & 1080 & 224 \\
\hline & & 49 & 13.4 & 1.7 & - & 22 & 4.2 & 40 & 9.6 & 650 & 72 \\
\hline \multirow[t]{2}{*}{5000} & 1.4 & 0 & 11.0 & 0 & 12 & 66 & 3.2 & 35 & 7.7 & 900 & 77 \\
\hline & & 66 & 6.6 & 2.2 & - & 9 & 2.4 & 63 & 2.6 & 90 & 26 \\
\hline \multirow[t]{2}{*}{10,000} & 1.5 & 0 & 5.9 & 0 & 5 & 21 & 1.5 & 38 & 2.1 & 100 & 4 \\
\hline & & 75 & 3.4 & - & - & - & - & - & - & - & - \\
\hline
\end{tabular}

a Yield stress and strain as determined by the Considère method [43]

b The true fracture stress $\left(\sigma_{\text {true }}\right)$ as calculated according to $\sigma_{f} \times\left(1+\left(\varepsilon_{f} / 100\right)\right)$ 


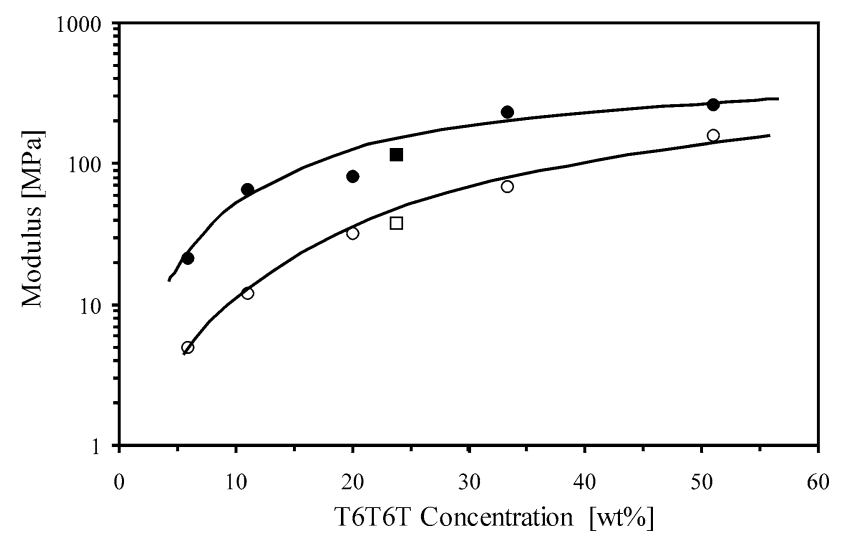

Fig. 4 The E-modulus (filled symbols) and storage modulus $\left(\mathrm{G}^{\prime}\right)$ (open symbols) of dry PEO copolymers as functions of the T6T6T content: $\square$ and $\square \mathrm{PEO}_{2000}, \bigcirc$ and $\bigcirc\left(\mathrm{PEO}_{600} / \mathrm{T}\right)_{y}$

mechanical properties of the copolymers, the $E$-modulus was plotted as a function of the actual T6T6T concentration, the concentration in the dry and the wet samples, respectively (Fig. 5).

At low water contents (i.e., for high values of the actual T6T6T concentration) the modulus-T6T6T relationship in the wet state was similar to that in the dry state. However, at high water contents, the modulus-T6T6T relationship in the wet materials was appreciably lower than in their dry counterparts. This was most evident for the $\mathrm{PEO}_{2000}$ copolymer that had absorbed a large quantity of water. It was assumed that the crystalline T6T6T phase was not affected by the water and that the reinforcing effect of the T6T6T crystallites remained unchanged. The reinforcing effect of the T6T6T crystallites (nano-ribbons) followed the fibre reinforced composite models [28, 33]. Most likely, the modulus of the polyether phase, as can be observed by the extrapolated modulus at zero T6T6T concentration, was

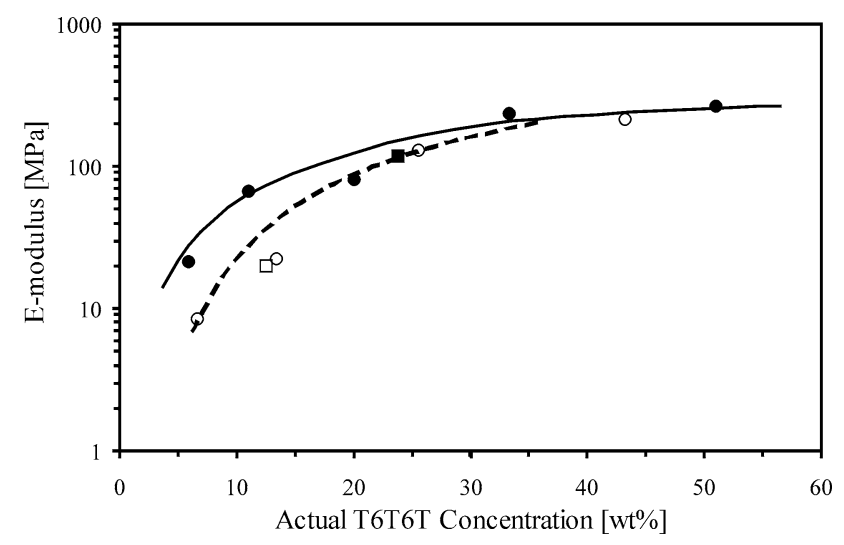

Fig. 5 The E-modulus of the $\mathrm{PEO}_{2000}-\mathrm{T} 6 \mathrm{~T} 6 \mathrm{~T}(\boldsymbol{\square}, \square)$ and $\left(\mathrm{PEO}_{600} /\right.$ $\mathrm{T})_{y}-\mathrm{T} 6 \mathrm{~T} 6 \mathrm{~T}$ copolymers $(\boldsymbol{O}, \mathrm{O})$ as a function of the actual T6T6T content: $\mathbf{\square}, \bigcirc$ dry; $\square$, $\bigcirc$ wet lowered by the plasticisation with water. Thus, as water was absorbed, the PEO phase became plasticised and at the same time the T6T6T concentration was lowered.

\section{Yield properties}

The yield point of segmented block copolymers is regarded as the onset of a large-scale deformation of the crystalline phase. Before the yield point, i.e., at low stresses, the crystallites are not (or very little) plastically deformed and the material has a highly elastic nature. In segmented block copolymers, the yield stress generally displays a linear increase with the crystallite concentration and the properties of the soft segments apparently have no effect on the yield stress $[26,45,46]$.

The yield stress of the studied block copolymers increased linearly with the actual T6T6T concentration in both the dry and the wet states (Fig. 6a). Moreover, the wet copolymers displayed identical relationships of yield stress versus actual T6T6T concentration. The observed variations in yield stress upon wetting were solely due to the changing T6T6T content whereas the plasticisation of the PEO phase had no effect.
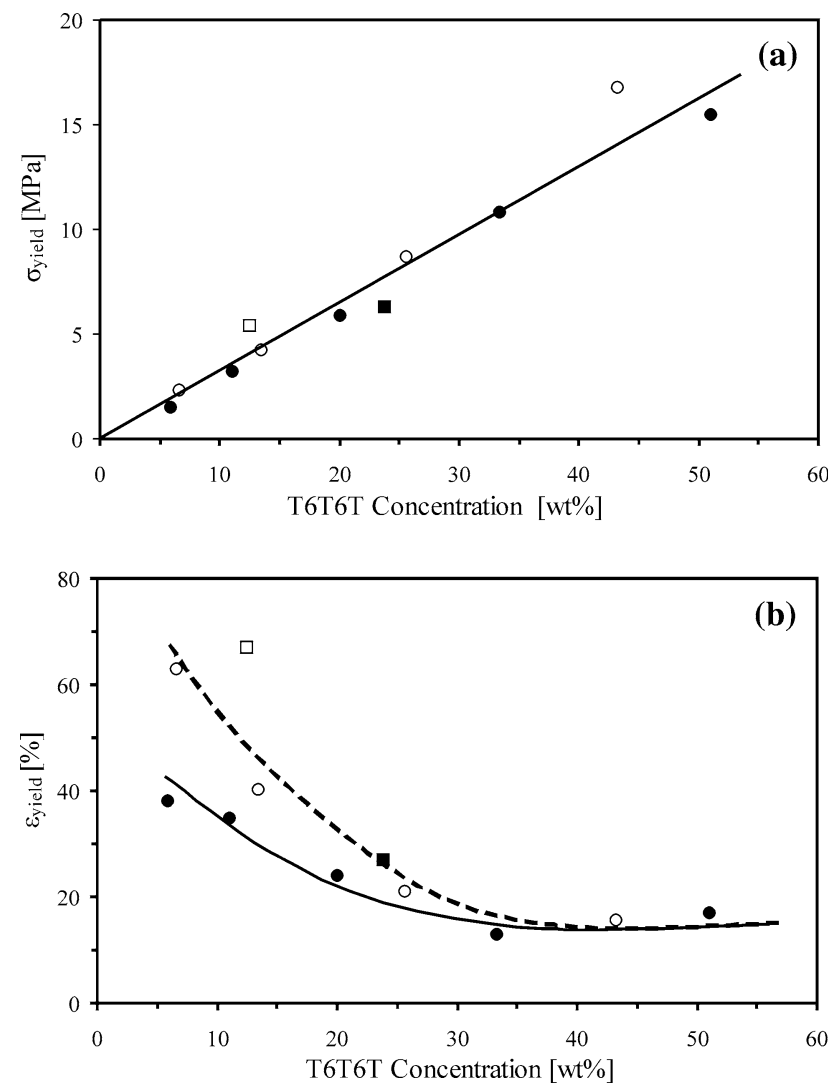

Fig. 6 a The yield stress and $\mathbf{b}$ the yield strain as functions of the actual T6T6T content for the $\mathrm{PEO}_{2000}-\mathrm{T} 6 \mathrm{~T} 6 \mathrm{~T}(\boldsymbol{\square}, \square)$ and $\left(\mathrm{PEO}_{600} /\right.$ $\mathrm{T})_{y}$-T6T6T copolymers $(\bullet, \bigcirc): \mathbf{\square}, \bigcirc$ dry; $\square, \bigcirc$ hydrated 
As shown in Fig. 6b, the yield strain increased with decreasing T6T6T content. Furthermore, the hydrated copolymers demonstrated a higher yield strain than their dry counterparts. This can be explained by the plasticising effect of water on the PEO segments. One should also notice the higher yield strains of the $\mathrm{PEO}_{2000}$ copolymer in both the dry and the wet state.

\section{Ultimate properties}

The ultimate properties of segmented block copolymers depend strongly on whether strain-hardening as well as a strain-induced crystallisation of the flexible segments can take place. Segments with a melting temperature above or just below its testing temperature can undergo straininduced crystallisation. Upon orientation, the melting temperature of the polyether as well as it crystallinity increases [43]. Thus, even polyethers with melting temperatures (in the isotropic state) below the test temperature can in some cases undergo strain-induced crystallisation. A copolymer displaying a strain-induced crystallisation effect at room temperature has been known to lose this effect as the test temperature was increased to above the melting temperature of the oriented segments [46]. However, at high temperatures, a certain amount of strain hardening was still observed. The fracture properties of the segmented block copolymers depend on the hard segment content and the number of (physical) crosslinks per chain. In the present study, the number of T6T6T segments per chain decreased with an increasing soft segment length of the copolymers (Table 1).

Fracture properties are known to be strongly dependent on the molecular weight of the copolymer [27, 43]. For copolymers of higher molecular weight, the strain-hardening is usually more significant. Among the studied block copolymers in the dry state, the stresses increased above the yield stress and this increase was more significant at strains above $200 \%$ (Fig. 3a). However such strain-hardening processes generally diminish with increasing $\left(\mathrm{PEO}_{600}-\mathrm{T}\right)_{y}$ segment length and this was also the case for the samples tested in the wet state (Fig. 3b). The fracture stresses of the copolymers in both the dry and wet states were found to increase linearly with the actual T6T6T concentration, as can be seen in Fig. 7a.

Besides the changing T6T6T concentration, the deceasing number of amide segments per chain was also believed to be of importance. At a low T6T6T concentration, the number of amide segments was small. The fracture stress values of $\mathrm{PEO}_{2000}$ were higher than for the $\left(\mathrm{PEO}_{600} \mathrm{~T}\right)_{y}$ copolymers and this might be due to the higher molecular weight of the copolymer. The fracture strains for the dry copolymers seemed to increase with decreasing fracture stress (Fig. 7b). However, for the copolymers with
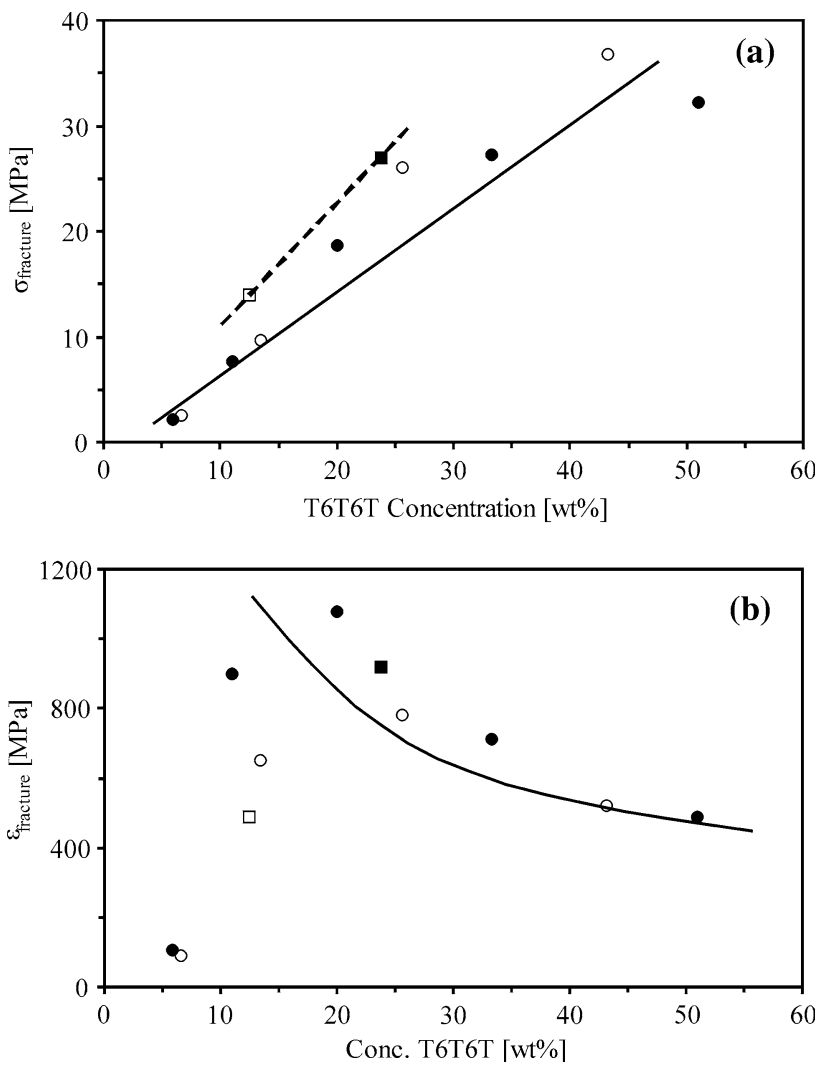

Fig. 7 The fracture a stress and $\mathbf{b}$ strain of $\mathrm{PEO}_{2000}-\mathrm{T} 6 \mathrm{~T} 6 \mathrm{~T}(\boldsymbol{\square}, \square)$, and $\left(\mathrm{PEO}_{600} / \mathrm{T}\right)_{y}-\mathrm{T} 6 \mathrm{~T} 6 \mathrm{~T}$ copolymers $(\mathbf{O}, \mathrm{O})$ as a function of the actual T6T6T content:

very few T6T6T segments per chain, the fracture strains were low. In the wet state, the fracture strains were especially low for high $\mathrm{H}_{2} \mathrm{O} / \mathrm{EO}$ values.

Upon increasing the fracture stress, the fracture strain often decreases, and since both these factors are important they can be combined into a single parameter: the true fracture stress. The true fracture stresses of the strainhardened segmented block copolymers have been found to increase with increasing inherent viscosity [46]. In the present case, Fig. 8 displays the true fracture stress as a function of the actual T6T6T content in the copolymers. It can be seen that in the dry state, the true fracture stresses were elevated at high T6T6T concentrations and depend very little on concentration.

It was a possibility that the true fracture stresses increased when going from $\mathrm{PEO}_{600}$ to $\mathrm{PEO}_{2000}$, and this might have been due to the increase in molecular weight. Such high values are typical for strain-hardened materials, and consequently, the low values of true stress at low T6T6T content in the dry state must have resulted from the absence of strain-hardening, as can be seen in Fig. 3. Thus, for non-strain-hardened systems with few T6T6T segments in the chain $(<3)$, the true fracture stresses were low and increased with T6T6T content. For the wet copolymers 


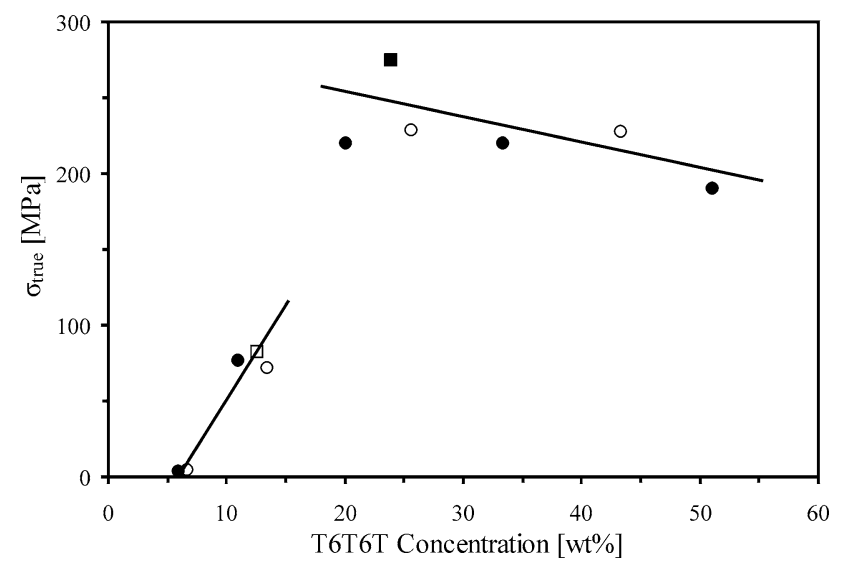

Fig. 8 The true fracture stress of the $\mathrm{PEO}_{2000}-\mathrm{T} 6 \mathrm{~T} 6 \mathrm{~T}(\boldsymbol{\square}, \square)$ and $\left(\mathrm{PEO}_{600} / \mathrm{T}\right)_{y}-\mathrm{T} 6 \mathrm{~T} 6 \mathrm{~T}$ copolymers $(\boldsymbol{O}, \mathrm{O})$ as a function of the actual T6T6T content: $\square$, $\bigcirc$ dry; $\square, \bigcirc$ hydrated

with low $\mathrm{H}_{2} \mathrm{O} / \mathrm{EO}$ values $(<1.5)$, the true fracture properties were as high as for the dry materials, whereas they were low at $\mathrm{H}_{2} \mathrm{O} / \mathrm{EO}$ values $>1.5$. A typical behaviour with regard to the true fracture stresses was observed for $\mathrm{PEO}_{2000}$ that displayed a high value in the dry state and a low value in the wet state. Since the wet $\mathrm{PEO}_{2000}$ had a very low melting temperature $\left(-39^{\circ} \mathrm{C}\right)$, no strain-induced crystallisation was expected to have occurred in this case.

\section{Conclusions}

The influence of water on the physical and tensile properties of segmented block copolymers, containing flexible hydrophilic poly(ethylene oxide) segments and monodisperse high-melting T6T6T segments, was investigated. The copolymers showed an exponential increase in water absorption with increasing PEO content and also the $\mathrm{H}_{2} \mathrm{O}$ / EO ratio was significantly raised. The presence of terephthalate groups in the PEO phase reduced the $\mathrm{H}_{2} \mathrm{O} / \mathrm{EO}$ ratio.

Upon wetting, both the $T_{\mathrm{m}}$ and $T_{\mathrm{g}}$ of PEO were lowered as a result of the solvent effect of water on the PEO crystallites and the plasticising effect on the PEO amorphous segments. The modulus and yield strength of the copolymers increased with T6T6T concentration while, at the same time, the yield strain decreased. Upon wetting, the modulus and yield stress decreased and the yield strain increased. This effect could partly be explained by the lowering of the T6T6T concentrations on wetting and at high water contents also by the plastisation of the PEO amorphous phase. The T6T6T nano-ribbon like crystals act as reinforcing fibres.

The ultimate properties of the segmented block copolymers were sensitive to several parameters: the T6T6T concentration, the molecular weight of the copolymer, the number of HS per chain and whether or not strain-hardening was possible. The fracture stresses in the dry state increased with T6T6T concentration, and this effect was possible partly due to the increase in the number of T6T6T segments per chain. Upon wetting, the fracture stress varied as the actual T6T6T concentration was altered. The fracture strains in the wet state also changed with the actual T6T6T concentration. However, the fracture strain for the wet $\mathrm{PEO}_{2000}$ was significantly reduced, probably due to the high $\mathrm{H}_{2} \mathrm{O} / \mathrm{EO}$ value giving rise to a strong reduction in the $T_{\mathrm{m}}$ of PEO and thereby reducing the possibility of strain crystallisation.

The true fracture stresses in the dry state were high for all copolymers if at least three T6T6T segments were present in the polymer chain. Moreover, they were independent of the T6T6T concentration and seemed to increase with molecular weight. Upon wetting, the true fracture stresses remained high for $\mathrm{H}_{2} \mathrm{O} / \mathrm{EO}$ values $<1.5$. Consequently, $\mathrm{PEO}_{2000}$ displayed low true fracture stresses as this material had a high $\mathrm{H}_{2} \mathrm{O} / \mathrm{EO}$ value, which was expressed in a significant lowering of the $T_{\mathrm{m}}$ of the copolymer and a reduced possibility of strain-induced crystallisation.

Acknowledgements The Dutch Polymer Institute (DPI, The Netherlands) is acknowledged for financial support of part of this research: project \#313 and \#497. Many thanks are expressed to Professor J. Feijen for fruitful discussions.

Open Access This article is distributed under the terms of the Creative Commons Attribution Noncommercial License which permits any noncommercial use, distribution, and reproduction in any medium, provided the original author(s) and source are credited.

\section{References}

1. Gebben B (1996) J Membr Sci 113:323

2. Stroeks A, Dijkstra K (2001) Polymer 42:117

3. Metz SJ, Mulder MHV, Wessling M (2004) Macromolecules 37:4590

4. Metz SJ, Potreck J, Mulder MHV, Wessling M (2002) Desalination 148:303

5. Bondar VI, Freeman BD, Pinnau I (1999) J Polym Sci B Polym Phys 37:2463

6. Bondar VI, Freeman BD, Pinnau I (2000) J Polym Sci B Polym Phys 38:2051

7. Johnson L, Schultze D (2000) Breathable TPE films for medical applications. Medical Device \& Diagnostic Industry, Los Angeles

8. Schneider NS, Illinger JL, Karasz FE (1994) Polymers of biological and biomedical significance. American Chemical Society, Washington, DC

9. Lee D, Lee S, Kim S, Char K, Park JH, Bae YH (2003) J Polym Sci B Polym Phys 41:2365

10. Schneider NS, Langlois DA, Byrne CA (1993) Polym Mater Sci Eng 69:249

11. Chen CT, Eaton RF, Chang YJ, Tobolsky AV (1972) J Appl Polym Sci 16:2105 
12. Schneider NS, Illinger JL, Karasz FE (1993) J Appl Polym Sci 47:1419

13. Yilgör I, Yilgör E (1999) Polymer 40:5575

14. Schneider NS, Dusablon LV, Snell EW, Prosser RA (1969) J Macromol Sci Phys 3:623

15. Kjellander R, Florin EJ (1981) Chem Soc Faraday Trans 77:2053

16. Deschamps AA, Grijpma DW, Feijen J (2002) J Biomater Sci Polym Ed 13:1337

17. Sakkers RJB, De Wijn JR, Dalmeyer RAJ, Brand R, Van Blitterswijk CA (1998) J Mater Sci Mater Med 9:375

18. Rault J, Le Huy HM (1996) J Macromol Sci Phys 35:89

19. Petrini P, Fare S, Piva A, Tanzi MC (2003) J Mater Sci Mater Med 14:683

20. Deschamps AA, Grijpma DW, Feijen J (2001) Polymer 42:9335

21. Harrell LL (1969) Macromolecules 2:607

22. Miller JA, Lin SB, Hwang KKS, Wu KS, Gibson PE, Cooper SL (1985) Macromolecules 18:32

23. Eisenbach CD, Baumgartner M, Guenter C (1986) In: Lai J, Mark JE (eds) Advances in elastomer and rubber elasticity. Plenium, New York

24. Eisenbach CD, Nefzger H (1989) In: Cumbertson WM (ed) Multiphase macromolecular systems, contemporary topics in polymer science, vol 6. Plenium, New York

25. Gaymans RJ, de Haan JL (1993) Polymer 34:4360

26. Niesten MCEJ, Gaymans RJ (2001) Polymer 42:6199

27. Krijgsman J, Gaymans RJ (2004) Polymer 45:437

28. Van der Schuur JM, Gaymans RJ (2006) J Polym Sci Polym Chem 44:4769

29. Versteegen RM, Sijbesma RP, Meijer EW (2005) Macromolecules $38: 3167$
30. Versteegen RM, Kleppinger R, Sijbesma RP, Meijer EW (2006) Macromolecules 39:772

31. Sheth JP, Klinedinst DB, Wilkes GL, Yilgor I, Yilgor E (2005) Polymer 46:7317

32. Das S, Klinedinst DB, Yilgor I, Yilgor E, Beyer FL, Cox DF, Wilkes GL (2006) J Macromol Sci B Phys 46:853

33. Biemond GJE, Feijen J, Gaymans RJ (2007) J Appl Polym Sci 105:951

34. Husken D, Feijen J, Gaymans RJ (2007) J Polym Sci A 45:4522

35. Husken D, Feijen J, Gaymans RJ (2008) Macromol Chem Phys 209:525

36. Husken D, Gaymans RJ (2008) Macromol Chem Phys 209:967

37. Vieweg R (1966) Kunststoff-Handbuch, vol 6. Hanser, Munchen

38. Arun A, Dullaert K, Gaymans RJ (2009) Macromol Chem Phys 210:48

39. Murthy NS, Stamm M, Sibilia JP, Krimm S (1989) Macromolecules 22:1261

40. Rault J, Gref R, Ping ZH, Nguyen QT, Néel J (1995) Polymer 36:1655

41. Rault J, Ping ZH, Nguyen QT (1994) J Non-Cryst Mater 172174:733

42. Hatakeyama H, Hatakeyama T (1998) Thermochim Acta 308:3

43. Niesten MCEJ, ten Brinke JW, Gaymans RJ (2001) Polymer 42:1461

44. van Krevelen DW (1990) Properties of polymers. Elsevier, Amsterdam, p 600

45. Holden G, Legge NR, Quirk RP, Schroeder HE (1996) Thermoplastic elastomers. Hanser Publishers, Munich

46. Biemond GJE, Gaymans RJ (2008) J Mater Sci 43:3689. doi: $10.1007 / \mathrm{s} 10853-008-2592-3$ 